Revista Iberoamericana, Vol. LXXVII, Núms. 236-237, Julio-Diciembre 2011, 1001-1018

\title{
LA NEGOCIACIÓN DE UNA IDENTIDAD GERMANO-ARGENTINA EN DER MEDIZINMANN AM LANIN, DE BERTHA KOESSLER-ILG
}

\author{
POR \\ JenNifer M. VALKo \\ East Carolina University
}

Conocida como la "araucana blanca" entre sus amigos mapuches, la inmigrante alemana Bertha Koessler-Ilg se radicó en San Martín de los Andes a principios del siglo xx. Reunió un amplio corpus de cuentos folklóricos indígenas y los publicó originalmente en alemán. Últimamente se ha despertado el interés en esta experta en folklore mapuche; en el año 2006 los nietos de la autora publicaron, en castellano, una nueva edición de su primer tomo de cuentos y dos manuscritos previamente inéditos en una trilogía titulada Cuenta el Pueblo Mapuche (Vallejos). Aunque hoy en día es famosa entre antropólogos chilenos y argentinos, la crítica no ha estudiado su primer libro, una suerte de memoria que brinda la oportunidad de explorar la negociación de identidad cultural germano-argentina en la cordillera de los Andes a fines del siglo XIX y principios del xx.

En 1940, Bertha Koessler-Ilg publicó Der Medizinmann am Lanin. Von der Arbeit eines deutschen Arztes in der patagonischen Kordillere en la distinguida casa editorial bonaerense de Ernst Beutelspacher. El texto formó parte de una serie titulada "Deutsches Werk in Südamerika” [Obra alemana en Sudamérica], y se amplió y republicó en 1963, para más tarde traducirse al español y aparecer en 2003 bajo el título El Machi del Lanín. Un médico alemán en la cordillera patagónica. El libro representa una obra nacida en lo que Mary Louise Pratt llamaría una "zona de contacto", es decir, un espacio en el cual grupos o individuos geográfica e históricamente separados entran en contacto y establecen relaciones continuas que muchas veces implican situaciones de discordancia y desigualdad (6). Es un entorno marcado por negociaciones a múltiples niveles, tanto en relación con tratos económicos como con respecto a la identidad personal o nacional. La estructura misma de Der Medizinmann am Lanin no sólo refleja esta zona de contacto sino que, considerando la idea acuñada por Stuart Hall, el libro se revela como "lugar de sutura”, un espacio de articulación de identidad cultural (2-6).

Este tema tiene relevancia por varios motivos. Las campañas inmigratorias vigorosas realizadas en Argentina a mediados del siglo xix ponían énfasis en atraer 
colonos germanos para "poblar" y "modernizar" el país. ${ }^{1}$ Aunque se ha documentado la historia de los inmigrantes germanos en el Río de la Plata, muy pocos investigadores han analizado su producción escrita. ${ }^{2}$ En tanto que intelectuales urbanos argentinos transcribieron el paisaje, la gente y las condiciones laborales presentes en el interior del país, los inmigrantes, en muchos casos nuevos nacionales cuyas familias se quedarán en Argentina por generaciones, también disponían de mercados para documentar el nuevo entorno, sus proyectos e interacciones, y, a la vez, sus autoconstrucciones identitarias en esta nación. Dichos autores inmigrantes escribían tanto para su comunidad inmigratoria como para lectores en sus países natales, por lo tanto sus obras revelan una retórica de adhesión a dos patrias. Existe, pues, una clase de textos escritos por inmigrantes que ilumina aspectos de identidad y cimentación nacional argentina que ha sido descuidada.

Últimamente estas cuestiones han sido examinadas por historiadores, lingüistas y sociólogos en el campo de estudios culturales alemanes quienes se ocupan de los múltiples aspectos relacionados con la cultura germana en el extranjero (más bien en Europa del Este, Estados Unidos, Canadá, Australia, Brasil, México y Paraguay). ${ }^{3}$ Sin embargo, dichas investigaciones son limitadas en primer lugar porque pocas veces realizan análisis de discurso de textos escritos por germanos expatriados y, en segundo lugar, porque no tratan de igual manera asuntos relacionados con los países anfitriones.

Con el fin de contribuir al contexto más amplio de investigación relacionado con estudios culturales argentinos del siglo xIx y principios del siglo xx, mi análisis muestra que publicaciones como las de Koessler-Ilg evidencian un hueco en la crítica. Fuentes en castellano producidas por miembros de colectividades étnicas, por ejemplo las de Guillermo Hudson, Paul Groussac y Alberto Gerchunoff, han sido estudiadas y forman

1 Cabe notar que los legisladores reclutaban noreuropeos, con una preferencia especial puesta en alemanes e ingleses. La inmigración como herramienta de modernización y cambio social formaba parte de la visión del primer presidente de la República Argentina, Bernardino Rivadavia, quien propuso transplantar campesinos y artesanos europeos para extirpar los vestigios del sistema colonial español e impulsar la creación de una nueva sociedad mixta que se beneficiara de su conocimiento y laboriosidad. Entre 1830 y 1850, Juan B. Alberdi y Domingo F. Sarmiento retomaron las ideas de Rivadavia y pusieron a la inmigración como eje de su proyecto de construcción nacional. Esta iniciativa se efectuó con vigor entre 1870 y 1914. Para más información sobre la política inmigratoria en Argentina, véase Castro (1991) y Devoto (2003).

2 Principalmente historiadores han investigado la presencia germana en Argentina; por ejemplo, Saint Sauveur-Henn (1995) hace un estudio exhaustivo de la inmigración alemana a la Argentina, Schobinger (1957) explora la inmigración y las primeras colonias agrarias suizas y Newton (1977 y 1992) analiza la historia y los cambios en la comunidad alemana en la capital bonaerense. Hay también una serie de libros publicados por Manrique Zago Ediciones que trazan las colectividades germanas en la Argentina, la fundación de varias colonias, clubes y escuelas, más los aportes de compañías e individuos ilustres, véase Presencia alemana y austriaca en la Argentina (1985), Presencia alemana en la Argentina (1992) y Los suizos en la Argentina (1995).

3 Excelentes ejemplos de estudios recientes se encuentran en Krista O’Donnell y otros (2005), y Mathias Schulze (2008).

Revista Iberoamericana, Vol. LXXVII, Núms. 236-237, Julio-Diciembre 2011, 1001-1018 ISSN 0034-9631 (Impreso) 
parte del canon. Sin embargo, el texto de Koessler-Ilg prueba la existencia de un conjunto de obras escrito por inmigrantes en otros idiomas que no ha sido reconocido ni tratado por investigadores. Este corpus complejiza el canon y merece la atención de críticos tanto por los temas que trata como por la forma misma empleada para organizar los textos. ${ }^{4}$

En este ensayo se examinará la primera edición de Der Medizinmann am Lanin y se explorarán dos hipótesis principales: primero, que el texto de Koessler-Ilg le permite a su autora hacer el papel tradicional de mujer alemana como defensora del Deutschtum ("germanidad”) y, segundo, que la forma misma de este texto híbrido y difuso crea una nueva identidad germano-argentina al subrayar la contribución de la autora al proyecto de construcción nacional argentino. ${ }^{5}$ A continuación se presentará la biografía de la escritora y el libro en su contexto histórico; luego se estudiarán los paratextos y, por último, el texto como autoetnografía y espacio de negociación de identidad nacional.

\section{BERTHA KoESSLER-ILG, FOLKLORÓLOGA AUTODIDACTA Y ENFERMERA}

Koessler-Ilg nació en 1881 en Obernzell (Baviera), Alemania. Inspirada por los métodos y la producción de los hermanos Grimm, su adolescencia marcó el comienzo de su pasión por cuentos folklóricos, los que recolectaba y publicaba en periódicos regionales (Machi 10). Mientras visitaba a su tío, el cónsul alemán en la isla de Malta, estudió maltés y árabe clásico con el fin de compilar canciones y relatos locales, y publicó en 1906 y 1909 libros de canciones, fábulas y cuentos malteses. ${ }^{6}$ Estas publicaciones

4 Aunque rastrear muestras de este corpus requiere trabajo de archivo adicional, ya se conocen varios libros publicados en la misma época que Der Medizinmann am Lanin que merecen ser analizados. Im Schatten des Calafate [A la sombra del calafate] (1925) de Otto Schreiber, trata las aventuras del autor en Patagonia. Las novelas Morath schlägt sich durch [Morath se busca la vida] (1933) y Morath verwiklicht einem Traum [Morath realiza un sueño] (1933), de Max René Hesse, siguen a un inmigrante alemán que arriba a la capital bonaerense y forma parte del equipo de médicos en el Hospital Alemán; ambas son romans à clef que critican las diferentes facetas de la comunidad alemana en la ciudad a principios del siglo Xx. Theodor Alemann ofrece un ensayo sobre la presencia germana en Argentina, de sus aportes y de cuestiones de identidad, véase, Die Zukunft des Deutschtums in America [El futuro de la Germanidad en América] (1917). Otra fuente de estudio rica son revistas culturales en alemán publicadas en Buenos Aires como Lasso (1933-1940) y Südamerika (1950-1970). Más datos sobre la literatura alemana en Argentina se encuentran en Presencia alemana en la Argentina (158-63).

5 Deutschtum (germanidad) se refiere a la cultura e identidad de germanoparlantes. La importancia de la manutención cultural se verifica no sólo en colectividades alemanas en Argentina sino también en otros países latinoamericanos, en Norteamérica y Australia. Historiadores del tema indican que colonos germanos trabajaban incansablemente para conservar sus prácticas culturales, tradiciones y lengua materna al establecer, por ejemplo, escuelas, clubes y periódicos. Ver Luebke (1990), Lorenzkowski (2002), O’Donnell (2005), LaVigne (2006) y Schulze (2008).

6 Publicó Maltesische Märchen und Schwänke aus dem Volksmunde Gessammelt [Cuentos malteses compilados de la voz del pueblo] (1906) y, junto con Hans Stumme, Maltesische Volkslieder im Urtext mit deutscher Übersetzung [Canciones folklóricas malteses originales y traducidas al alemán] (1909).

Revista Iberoamericana, Vol. LXXVII, Núms. 236-237, Julio-Diciembre 2011, 1001-1018 ISSN 0034-9631 (Impreso) 
fueron bien recibidas en su momento y constituyen verdaderos logros, ya que en la Alemania de aquella época, y hasta bien entrado el siglo xx, las alemanas sufrían una fuerte desigualdad en la sociedad. Hasta 1908 la mayoría de las universidades no aceptaba a mujeres, quienes además no podían participar en política; de hecho, no consiguieron el derecho al voto sino hasta 1918. Luego de volver a Alemania, la autora se recibió de enfermera en la Escuela de Enfermería de la Cruz Roja de Frankfurt, donde conoció a su esposo, Rodolfo (Rudolf) Koessler, un médico que trabajaba en la misma ciudad y con quien se casó en 1912 (Machi 10).

Hacerse enfermera era común entre las mujeres a fines del siglo XIx y principios del siglo xx en Alemania. Entre 1870 y 1914 los estados europeos anexaron territorios en África, Asia y el Pacífico, en lo que sería una tarea imperialista que involucraba mujeres. Lora Wildenthal afirma que, a pesar de las limitaciones impuestas a las mujeres alemanas en el ámbito público, existían organizaciones y espacios relacionados con el proyecto colonialista que les ofrecían la oportunidad de liberarse de roles tradicionales, educarse, ganarse la vida y aportar al desarrollo de la patria. Uno de estos espacios era la enfermería, cuyo oficio cumplía con nociones conservadoras del rol femenino en la sociedad porque combinaba dos papeles tradicionales: por una parte, recurría a la vocación tradicional cristiana (para hombres y mujeres) del cuidado de enfermos y, por otra, se servía de la noción de maternidad. Alabada como profesión patriótica durante las Guerras Napoleónicas a principios de siglo y las de unificación nacional en la década de 1860, la enfermería se profesionalizó y se feminizó en la segunda mitad del siglo XIx (Wildenthal 12-13). En el contexto imperial alemán, las enfermeras enviadas a las colonias eran como un ejército de potenciales esposas y madres para hombres radicados en aquellas regiones. Por la escasez de alemanas en las colonias, los hombres alemanes empezaron a mezclarse con las mujeres del lugar. En Alemania, esta mezcla no era bien recibida e incluso se prohibió. ${ }^{7}$ Enviar enfermeras suponía un beneficio secundario: un aumento en matrimonios entre alemanes para conservar la "pureza de la raza”. Asimismo, se aseguraría el asentamiento de amas de casa y madres modelo que desempeñarían el trabajo tradicional femenino de administrar la casa y criar a los niños siguiendo las prácticas culturales germanas respecto a lengua, tradiciones y formación escolar. Según Wildenthal, las mujeres en este contexto se transformaron en símbolos de la cultura alemana y agentes de progreso, y eran percibidas como protectoras de Deutschtum y portadoras de buenos modales, costumbres y nacionalismo. Entre 1885 y 1907 fueron establecidas diversas asociaciones que se dedicaban al entrenamiento de mujeres para ser enfermeras en las colonias alemanas, y la Cruz Roja alemana, donde estudió Bertha Koessler-Ilg, estaba entre las más importantes (Wildenthal 21-26, 38). ${ }^{8}$

7 Para más información sobre el contexto colonial alemán y el papel femenino, ver O’Donnell (2005).

8 Wildenthal explica que hacia 1914 la Cruz Roja junto con Las Ligas Patrióticas de Mujeres ya tenían 800.000 miembros y 52 casas matrices que empleaban más de 6.000 enfermeras en las colonias alemanas $(38,222)$.

Revista Iberoamericana, Vol. LXXVII, Núms. 236-237, Julio-Diciembre 2011, 1001-1018
ISSN 2154-4794 (Electrónico) 
Rechazando una oferta en Samoa Occidental, su esposo aceptó un puesto de trabajo en el Hospital Alemán en Buenos Aires donde ejerció desde 1913 hasta 1920. ${ }^{9}$ Bertha y su marido se radicaron en San Martín de los Andes, en el territorio de Neuquén, en $1920{ }^{10}$ Se quedaron en el país, desempeñaron sus oficios y criaron a sus seis hijos en el lugar. Hoy en día, Koessler-Ilg es conocida como folkloróloga autodidacta y por sus colecciones de cuentos mapuches que comprenden un amplio corpus reunido durante cuarenta y cinco años de conversaciones con diversos informantes indígenas (Vallejos).

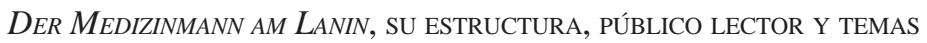

La estructura del libro es compleja porque se inicia con dos prólogos (los cuales se analizarán más adelante), tiene una voz narrativa que oscila entre la primera y la tercera persona, y además presenta tres hilos narrativos: la labor de Rodolfo como médico, el trabajo de Bertha como folkloróloga y finalmente las prácticas culturales de sus informantes amerindios. Der Medizinmann am Lanin está dividido en siete secciones que presentan temas como el valle de San Martín, el trabajo médico y doméstico, la población local, visitas, etc. Relata aproximadamente sesenta y cinco anécdotas que detallan los primeros veinte años que la pareja vivió en San Martín de los Andes y lo transformó en su hogar permanente. El texto incluye escasas definiciones de palabras del español o de expresiones idiomáticas, lo cual sugiere que se escribió principalmente para la comunidad germana en Argentina mayormente bilingüe, de clase media y alta. El glosario al final de la obra define frases en español y mapuche para una audiencia germanohablante monolingüe más bien radicada en el extranjero.

El público lector es algo difícil de concretar por las múltiples generaciones de inmigrantes germanos presentes en el país. ${ }^{11}$ Los estudios de la comunidad germana

9 Samoa Occidental fue colonia alemana desde 1900 hasta 1919.

10 Situado en el límite con Chile, ese pueblo agreste en la Región de los Lagos argentina era la tierra natal de varios grupos de mapuches. Con la aclamada Campaña de Desierto (1879-1883), el estado argentino se adueñó de los territorios amerindios y empezó a integrar las nuevas propiedades en redes de producción nacionales e internacionales (Bandieri 224; Castro 114). Similar a los Estados Unidos, municipalidades como San Martín de los Andes empezaron como fortalezas militares. Fundado en 1898 por el general Rudecindo Roca, el pueblo se pobló, al comienzo, con soldados de caballería. Se confinaron las poblaciones aborígenes locales en reservaciones (“colonias”) y los terrenos restantes fueron vendidos a compañías privadas de aserraderos y agropecuarios que, a su vez, atrajeron empresarios a la región desde Chile (Torres 256-57; Blanco 165).

${ }^{11}$ Definir la colectividad germana en Argentina es tarea compleja. Para la fecha de publicación de Der Medizinmann am Lanin había una gran variedad de orígenes, generaciones y tendencias políticas y culturales. Existían miembros que ya formaban parte de una cuarta generación en el país, los cuales desempeñaban sus deberes cívicos y se consideraban argentinos con una conciencia, inclinación y orgullo respecto a su herencia germana. Había también subgrupos de la comunidad más apegados a la noción

\footnotetext{
Revista Iberoamericana, Vol. LXXVII, Núms. 236-237, Julio-Diciembre 2011, 1001-1018
ISSN 2154-4794 (Electrónico)
} 
en Argentina realizados por el historiador Ronald C. Newton indican que se veían casos significativos de asimilación de hombres alemanes en Argentina: por un lado, porque faltaban mujeres alemanas radicadas en el país y, por otro, para lograr ascender socialmente: "By the 1920s, many well-known founding families-Altgelt, Arning, Bemberg, Bracht, Bullrich, Bunge, Frers, Holmberg, Seeber, Stegmann-were criollo oligarchs in all but patronymic and retained only pro-forma contact, if any at all, with the German collectivity” ('Nazi Menace' 29). No obstante, el prestigio de la cultura alemana se mantenía por sobre la argentina en la clase media y alta. Si bien existía asimilación, había normas socioeconómicas que exigían la preservación de la cultura germana, al menos en apariencia. Señala Newton que, por ejemplo, una mujer criolla sería aceptada como esposa si mantenía una casa alemana, las tradiciones y celebraciones germanas, y si se educaba a los hijos en escuelas alemanas asegurando que pudieran lograr un nivel de alemán aceptable-pero esta costumbre no eliminaba la influencia argentina, sino que facilitaba un rango de identidades duales ('Nazi Menace' 30). Son estos grupos también los que fundaban y asistían a clubes, escuelas e instituciones sociales para mantener el Deutschtum. Todo esto implica que el público lector germano-argentino de Koessler-Ilg formaba parte de la clase media y alta que había recibido cierto nivel de instrucción en el idioma y que se identificaba tanto con la cultura argentina como con la germana con mayor o menor grado. Este hecho puede también explicar el lenguaje empleado por la escritora, el cual es más bien simple y accesible para todo tipo de lector.

Por su profesión de enfermera, las anécdotas de Koessler-Ilg suelen relatar su participación en acontecimientos médicos y ofrecen descripciones detalladas de casos relacionados con sus empobrecidos vecinos amerindios y mestizos. La autora narra los fracasados tratamientos administrados por las machis locales y, en contraste, hace resaltar el comportamiento desinteresado de su esposo al realizar su labor muchas veces gratuitamente.

El contenido del libro se asemeja a memorias y novelas escritas por alemanas que vivieron en las colonias. Según la historiadora Wildenthal, estos textos abundaban entre 1900 y 1920, y solían retratar a la mujer ama de casa (Hausfrau) o granjera (Farmersfrau) como hábil administradora frente a grandes desafíos y exitosa protectora de integridad nacional, moralidad y pureza étnica (151-52). Der Medizinmann am Lanin sigue ese patrón pero lo transforma al subrayar el papel de Koessler-Ilg como esposa de médico y enfermera, e incorporar cuentos folklóricos aborígenes que la autora recogió de los pacientes y sus familias.

Pocas anécdotas tratan el tema de los quehaceres de la casa, la maternidad y la crianza de los niños, mientras que la mayoría retrata el uso del hogar como hospital, los

de conservar sus raíces y prácticas culturales alemanas "puras” y que se mantenían separados. Para información más específica, ver Newton (German 150-56; ‘Nazi Menace’ 29-30).

Revista Iberoamericana, Vol. LXXVII, Núms. 236-237, Julio-Diciembre 2011, 1001-1018 ISSN 0034-9631 (Impreso) 
síntomas e higiene de los pacientes, y las diferencias culturales en el tratamiento médico. La autora deja ver cierto desprecio cuando describe los hogares, prácticas domésticas y procedimientos medicinales indígenas para acentuar la superioridad cultural europea por sobre la mapuche. ${ }^{12}$ Brinda asimismo una representación escrita de un espacio social en el margen del país y de la labor que ella considera un desafío para los miembros de esta comunidad inmigrante fronteriza.

\section{Der MEDIZINMANN Am LANin, CONTEXTO HISTÓRICO Y PATRIOTISMO}

Aunque no había ninguna colonia formal alemana en Sudamérica, existía en Buenos Aires un grupo pudiente de comerciantes y bancarios alemanes que había llegado a principios del siglo xıx. Hacia 1850 se radicaron en Argentina colonos agrarios germánicos que formaban parte de iniciativas privadas de colonización y que trabajaban en conjunto con el gobierno argentino. La presencia de una comunidad alemana ya arraigada en el país provocó un marcado interés imperialista alemán en Argentina a fines del siglo xIx y principios del siglo xx. ${ }^{13} \mathrm{Si}$ bien el interés de parte de sociedades inmigratorias y empresarios en Alemania se inclinaba más por el imperialismo informal (económico) en el Río de la Plata, se reproducía en Argentina el discurso de superioridad germana, surgido después de la unificación en 1871, que celebraba sus orígenes, carácter y hazañas. Durante el reinado de Guillermo II esta retórica nacionalista tuvo un papel importante por el deseo de ampliar la influencia y poder alemanes en el mundo, y era empleada por políticos y comerciantes con el fin de justificar anexiones en África y en el Pacífico. Notablemente, como bien explica Lilia Ana Bertoni, existía entre los gobernantes argentinos finiseculares el temor de la anexión alemana. Esta amenaza percibida desencadenó discusiones y proyectos para fortalecer la imagen de Argentina como nación y para consolidar el patriotismo entre las colectividades de inmigrantes en el país (128-59). Dudas y debates similares resurgieron en Sudamérica con las campañas propagandísticas del Tercer Reich en la década de 1930. Asimismo, la retórica patriótica alemana circulaba en la colectividad germana en Argentina e incluso era utilizada por algunos intelectuales de esa comunidad para resaltar la influencia positiva que había tenido el Deutschtum en el país adoptivo.

${ }^{12}$ Nancy R. Reagin explora los vínculos entre identidad cultural alemana y vida doméstica en la época. Explica que la identidad nacional empezaba a cobrar más importancia en ámbitos domésticos, especialmente en publicaciones para amas de casa donde se manifestaba la superioridad alemana en la limpieza y manutención del hogar por sobre mujeres de otros países: estos rasgos fueron subrayados especialmente en las memorias y revistas de amas de casa coloniales que circulaban entre mujeres burguesas alemanas a fines del siglo xIx hasta bien entrado al sigo xx (55-61).

${ }^{13}$ Woodruff Smith (1978) ofrece información sobre el imperialismo alemán en general, mientras Ian Forbes (1978) y Walter Bernecker y Thomas Fischer (1996) analizan la relación entre Alemania y América Latina en este período y describen el programa imperialista informal alemán en la región.

\footnotetext{
Revista Iberoamericana, Vol. LXXVII, Núms. 236-237, Julio-Diciembre 2011, 1001-1018
ISSN 2154-4794 (Electrónico) 
La primera edición de Der Medizinmann am Lanin (1940) apareció durante una época tumultuosa para la comunidad germana en Argentina, pues se encontraba en una etapa de decadencia y era consumida por luchas de poder internas. ${ }^{14}$ Entre los años 1937 y 1939 una serie de escándalos difundida por la prensa bonaerense sacudió la opinión pública respecto a este grupo étnico y puso en tela de juicio su adhesión al país. El escándalo más grave implicaba a la embajada alemana en un complot para anexar secciones de la Patagonia para proyectos imperialistas del Tercer Reich. La mala opinión pública se manifestó en protestas y violencia dirigida hacia los alemanes que vivían en el país (Newton, 'Nazi Menace' 184-205). ${ }^{15}$ Los paratextos en el libro de Koessler-Ilg parecen dialogar con el contexto histórico en el cual se publicó, puesto que resaltan las buenas obras y el patriotismo de inmigrantes germanos en Argentina.

\section{LOS PARATEXTOS COMO RESPUESTA Y DEFENSA}

El título y los prólogos son paratextos importantes porque señalan la relación entre el texto y su marco, y crean expectativas en el público lector al indicar que el tema principal es el trabajo de un médico alemán en Patagonia. Como ya se mencionó, el libro tiene dos prólogos, el primero escrito en castellano por el Dr. Mariano J. Barilari y el segundo por Koessler-Ilg en alemán. Notablemente, los prefacios emplean lenguaje e imágenes que remiten al discurso oficial argentino decimonónico sobre la Patagonia y el papel de los inmigrantes en la nueva patria. Ambos además enfatizan los estereotipos de la región como lugar rústico e inhóspito, y su transformación en un espacio ya civilizado que ofrece muchas comodidades. Existen asimismo discordancias significativas entre los dos prólogos que revelan el libro como zona de contacto, las cuales a su vez constituyen una negociación respecto a la incorporación e identidad de los inmigrantes germanos en Argentina.

Por un lado, Barilari, compañero de Rodolfo Koessler en la Universidad de Heidelberg y socio fundador de la Institución Cultural Argentino-Germana, confirma el talento del médico y destaca su "carácter noble” (Der Medizinmann 3). ${ }^{16}$ Retrata a Bertha y Rodolfo como "verdaderos héroes en los dominios de Lanín, -y un nuevo hogar argentino en

14 Newton (1977 y 1992) hace un estudio importante del desarrollo de la comunidad alemana en Buenos Aires desde mediados del siglo XIx, con énfasis en el siglo xx.

15 Según un informe secreto, la embajada alemana recopilaba datos sobre las defensas argentinas en Patagonia y su potencial económico porque las autoridades alemanas pretendían establecer colonias agrícolas en la zona. El documento suponía además que la región era considerada terra nullius, es decir, disponible para anexión. Esta intriga produjo una reacción fuerte de parte de la administración argentina en forma de redadas policiales a oficinas del partido nazi, organizaciones, clubes, asociaciones y bares germanos en la capital y los lugares más remotos en Patagonia (Newton, 'Nazi Menace' 184-205).

${ }^{16}$ El Dr. Barilari también era pintor. Para más información, ver: Museo Genaro Pérez, "Mariano Barilari”. $<$ http://www.agora.com.ar/museogp/mt2005/mtemp-MB.htm>.

Revista Iberoamericana, Vol. LXXVII, Núms. 236-237, Julio-Diciembre 2011, 1001-1018
ISSN 2154-4794 (Electrónico) 
éste [sic] gran país de libertad y progreso!” (Der Medizinmann 3). La expresión “nuevo hogar argentino" implica dos procesos simultáneos en cuanto a la transformación del territorio y el establecimiento en el nuevo país. Primero, evoca la transformación por medio de la colonización inmigrante de tierras aborígenes consideradas "desierto" en la retórica decimonónica del estado argentino, es decir, hace referencia a la realización exitosa de planes inmigratorios oficiales decimonónicos para poblar y desarrollar terrenos nacionales. En segundo lugar, la expresión de Barilari sugiere que Argentina es la nueva morada permanente de esta pareja extranjera.

Paradójicamente, Barilari no reconoce el trabajo de Bertha como autora del libro que presenta; se concentra, en cambio, en la actividad de Rodolfo. El prologuista argentino describe la obra de la siguiente manera:

Esta simpática obra “El Machi del Lanín” [... ] servirá como ejemplo: es labor silenciosa de un hombre que ha dedicado los esfuerzos de su vida madura al bienestar del país de su elección y de una mujer abnegada que todo lo supo sacrificar para acompañarlo en su ruda ruta cordillerana. (Der Medizinmann 4)

El prólogo de Barilari se dirige a un público lector germanoparlante bilingüe, refiriéndose a Rodolfo como "mi viejo amigo" y "noble” con el fin de manifestar la honradez de Rodolfo y su confianza en él. Marcando la estadía continua de la pareja en el territorio, Barilari reconoce su patriotismo al emplear expresiones como “nuevo hogar argentino”y "país de su elección”, y retrata a los cónyuges como "héroes” arraigados en la zona más remota de la nación sugiriendo que sus sacrificios han traído "civilización” y "progreso" al lugar. En efecto, el prologuista implica que la sola presencia de Bertha y las obras concretas de su marido contribuyeron al desarrollo del país. Sin embargo, lo que no menciona nunca Barilari es la nacionalidad de sus amigos Bertha y Rodolfo. Aunque esta introducción indica la amistad germano-argentina, y a nivel simbólico confirma que la simpatía entre las dos comunidades les permite compartir un lugar tanto textual como geográfico, hay también otra singularidad: el espacio textual es alemán, donde ha sido invitado un argentino. La sección de Barilari es la única en castellano; por lo tanto, el argentino no sólo es minoría sino que también su voz aparece enmarcada por el alemán. Hay en el texto un proceso de adopción inversa, en el cual el prologuista argentino es huésped y los inmigrantes alemanes los anfitriones. Este fenómeno textual refleja y subraya la zona de contacto en el cual nació el libro.

Por otro lado, en su prefacio, la autora informa sobre las circunstancias de la publicación y su compromiso con Argentina, enfatizando el trabajo no sólo de su marido sino también el suyo como etnóloga y escritora. Utilizando el tópico de humildad, Koessler-Ilg en su prólogo señala que escribió el libro como respuesta a peticiones para que retratara el ambiente cotidiano y laboral en la cordillera patagónica a través

\footnotetext{
Revista Iberoamericana, Vol. LXXVII, Núms. 236-237, Julio-Diciembre 2011, 1001-1018
ISSN 0034-9631 (Impreso)
} 
de las obras de su esposo (Der Medizinmann 5). La escritora confirma su adhesión a Argentina cuando declara:

[wir solten uns immer daran erinnern] daß wir nie "gutes Werk” oder “Opfer” sagen sollten, sondern “heilige Pflicht” dem Wahlvaterlande gegenüber, der wir uns aus größter Dankbarkeit heraus, schon weil es das Vaterland unserer Kinder ist, niemals entziehen dürfen. (Der Medizinmann 6-7) $)^{17}$

Esta afirmación se refiere a múltiples temas relacionados con inmigración, identidad nacional y trabajo en el contexto de un "nosotros” explícito en la cita. Del mismo modo que la autora, sus narratarios forman parte de la comunidad alemana en Argentina, por lo tanto esta cita alude a sus grandes aportes a la nación austral y a la decisión consciente de quedarse en la “patria elegida”. Asimismo, plantea que sus hijos nacidos en Argentina son a fin de cuentas argentinos, alineando la colectividad alemana a la que se dirige Koessler-Ilg con el perfil de aquella población ideal que los políticos decimonónicos locales buscaban para los agresivos programas de inmigración con el fin de transformar el carácter nacional y modernizar su país. La lealtad de Koessler-Ilg queda demostrada también por el hecho de que el libro está basado en sus veinte años de residencia en Argentina, el cual funciona como documento que atestigua su compromiso en hechos.

En contraste con el texto de Barilari, en el prólogo de Koessler-Ilg abunda el gentilicio "Deutsch” [alemán] para subrayar su origen: "Lebens- und Schaffensgebiet deutscher Menschen in der patagonischen Kordillere” [región de residencia y trabajo de gente alemana en la cordillera patagónica]; “Arbeit eines unermüdlichen deutschen Arztes” [el trabajo de un médico alemán incansable] (Der Medizinmann 5; énfasis míos). La repetición del adjetivo vincula a Koessler-Ilg y a su esposo con tradiciones y prácticas germanas, y a su vez define sus acciones de acuerdo a referentes culturales no argentinos. En las páginas iniciales también relaciona el trabajo de su marido con la nación originaria:

Und Gerade weil für die Beurteilung eines Volkes immer wieder unendlich viel abhängt von dem Auftreten und dem Wirken des Einzelnen, so ist es auch die Arbeit des deutschen Arztes in der abgeschiedenen patagonischen Kordillere ein deutsches Werk, würdig neben glanzvollern und berühmteren geschichtlichen Taten genannt zu werden. (Der Medizinmann 5; énfasis míos) ${ }^{18}$

17 “[Debemos acordarnos siempre que] en lugar de hablar de 'buenas obras' y de 'sacrificio', debemos hablar de un 'deber sagrado' hacia la patria elegida, que por nuestra mayor gratitud nunca podemos retirar ya que es la patria de nuestros hijos”. Todas las traducciones son mías.

18 "Al evaluar los méritos de un pueblo [nación], una y otra vez mucho depende de la acción y el comportamiento de cada uno de sus integrantes. Así, la labor de un médico alemán en la lejana cordillera

Revista Iberoamericana, Vol. LXXVII, Núms. 236-237, Julio-Diciembre 2011, 1001-1018

Revista Iberoamericana, Vol. LXXVII, Núms. 236-237, Julio-Diciembre 2011, 1001-1018
ISSN 2154-4794 (Electrónico)


La escritora alude a la serie "Deutsches Werk in Südamerika" [Obra alemana en Sudamérica], en la cual se publicó su libro, y va más allá de presentarlo como una obra literaria: sitúa su trabajo y los hechos que expone en el contexto más amplio de actividades culturales y profesionales positivas efectuadas por alemanes en Argentina. Subrayar su origen al repetir el adjetivo de nacionalidad no borra su adhesión al país adoptivo, sino que muestra un pacto implícito en la zona de contacto donde reside: revela conciencia y respeto por dos culturas, la alemana y la argentina. Como consecuencia, implica que las sencillas obras de su marido y las suyas, como escritora y compiladora, son evidencia de la forma en la cual inmigrantes alemanes ayudaron a realizar el proyecto nacional "civilizador" argentino de fines del siglo xix y principios del siglo xx. Al mismo tiempo exige que se reconozcan los modestos aportes de los miembros de la comunidad germana en la historia nacional del país. Este proceso de negociación apunta a la "sutura" de una identidad dual definida por el orgullo de, por un lado, su origen alemán y, por otro, de sus aportes como inmigrante integrada a la nueva patria. ${ }^{19}$ Parece exagerado que Koessler-Ilg exija tanto reconocimiento puesto que su público lector es mayormente germano-argentino. No obstante, dado el rango de diversidad en esta colectividad y el apego a su cultura es muy probable que Koessler-Ilg se esté dirigiendo a los miembros de la oligarquía argentina de ascendencia germana.

Considerando el contexto en el cual se publicó Der Medizinman am Lanin, los escándalos en la prensa sobre el complot patagónico y el cuestionamiento de la lealtad de los alemanes respecto a Argentina, se puede argumentar que los prólogos sirven como respuesta y defensa a la situación histórica pero también cultural en la que se encuentra la autora. Por una parte, Barilari, ciudadano argentino, presenta una pareja inmigrante ejemplar cuya "labor silenciosa” contribuye a su "país de elección”. Sus descripciones puntuales contrastan con las imágenes de la prensa y reafirman la adhesión de Bertha y Rodolfo a la nación. Por otra parte, Koessler-Ilg asume el rol tradicional femenino alemán de buena protectora de Deutschtum: defiende el origen cultural y la integridad de su familia, y de otros trabajadores germanos, cuando emplea repetidamente el adjetivo "Deutsch" para hacer resaltar las acciones de los integrantes individuales, ejemplificadas en este caso por su marido. Sin embargo, la escritora simultáneamente utiliza el texto para salir de ese mismo papel tradicional femenino alemán al destacar su propio trabajo y aporte intelectual al patrimonio argentino cuando manifiesta:

patagónica es también una obra alemana, que merece ser considerada como tal junto a proezas históricas más ilustres y conspicuas".

19 Según Hall y Du Gay, la identidad se debe considerar "un punto de sutura” entre discursos y prácticas. El acto de suturar es la articulación entre sujetos y representaciones culturales para producir dichas identidades (2-6).

Revista Iberoamericana, Vol. LXXVII, Núms. 236-237, Julio-Diciembre 2011, 1001-1018
ISSN 0034-9631 (Impreso) 
Sie [diese Skizzen] bringen auch-was mich in tiefster Seele froh macht-einen kleinen Teil meiner Sammlung volkskundlichen Gutes. Sie sind nicht so sehr für den Sachverständigen als für die Allgemeinheit bestimmt, die wenig gerade darüber gehört haben mag: Ueber dieses uralte und doch so bezaubernd gegenwartsfrische Land der Araukaner. (Der Medizinmann 6) ${ }^{20}$

La recopilación de patrimonio cultural forma parte de mecanismos de construcción nacional a fines del siglo xix y principios del siglo xx en países como Alemania y Argentina. El interés por rastrear muestras de pueblos autóctonos y sus tradiciones originales ayuda a crear una historia unificada del pasado de la nueva nación. KoesslerIlg indica en el primer capítulo que los aborígenes pronto serán transformados en mito por la acelerada ola de civilización de la que ella misma es parte (Der Medizinmann 14). Así, la autora utiliza el texto para marcar su propia contribución como mujer al proyecto oficial de construcción nacional argentino, la de conservar el pasado amerindio para el acervo nacional argentino. Como se verá a continuación, este gesto subvierte el propósito original del libro.

AutOETNOGRAFÍA Y LA NEGOCIACIÓN DE IDENTIDAD NACIONAL

Un aspecto significativo de Der Medizinmann am Lanin es su forma híbrida o, en palabras de Clifford Geertz y Caroline Brettell, su condición de género difuso (blurred genre) (Brettell 223). Dentro de los géneros difusos, la autoetnografía es el que mejor refleja las características de este texto. Si bien el término “autoetnografía” ha sido utilizado y redefinido por críticos literarios, antropólogos y sociólogos desde los años 1970, la siguiente definición de Deborah Reed-Danahay es relevante para el presente análisis:

Autoethnography is ... a form of self-narrative that places the self within a social context. It is both a method and a text, as in the case of ethnography. Autoethnography can be done by either an anthropologist who is doing 'home' or 'native' ethnography or by a non-anthropologist/ethnographer. It can also be done by an autobiographer who places the story of his or her life within a story of the social context in which it occurs. (9)

Es difícil encasillar a la escritora en un campo preciso y clasificar su obra en uno u otro género, pues Der Medizinmann am Lanin combina varios: ensayo, biografía (de la labor de su esposo), autobiografía (de su propio oficio), etnografía (recoger y describir la cultura y las tradiciones mapuches a través de informantes) y el cuento (presentar

20 "Ellos [los bosquejos que componen el libro] también traen -lo que me alegra en la profundidad del alma- una pequeña parte de mi colección de patrimonio cultural. No están destinados a los expertos en el campo sino al público general que probablemente conozca poco acerca del antiquísimo y a la vez tan mágico y actual país de los araucanos".

Revista Iberoamericana, Vol. LXXVII, Núms. 236-237, Julio-Diciembre 2011, 1001-1018

ISSN 2154-4794 (Electrónico)
ISSN 0034-9631 (Impreso)


mitos mapuches). Sin embargo, a mi juicio, como autoetnografía se trata de una variante del ensayo y su aparente desorganización no es una debilidad, sino una estrategia que fortalece el texto haciéndolo más flexible. Desde el punto de vista analítico, la estrategia permite descubrir más concretamente cómo el libro de Koessler-Ilg refleja esta zona de contacto que es San Martín de los Andes a nivel textual. Es más, el libro manifiesta a través de su organización el arte de negociar o "suturar" la identidad binacional de la autora. Aunque su objetivo para escribir el libro fue destacar las obras de su marido como médico rural y de "esbozar cuadros realistas de la vida y acciones de alemanes" en la cordillera patagónica, Koessler-Ilg proporciona la relación paralela de su trabajo como recolectora de información in situ: el texto incluye cuentos folklóricos, datos sobre las prácticas medicinales de las machis, las condiciones de vida y enfermedades de sus vecinos aborígenes, y detalles sobre sus valores culturales además de los de sus amigos e informantes mapuches (Der Medizinmann 5). El resultado es, por tanto, el entretejimiento de tres hilos narrativos y, hasta cierto punto, la producción de un texto polifónico. La mezcla de voces, mayormente la de Koessler-Ilg con la de sus informantes amerindios, les permite hablar, contar cuentos y relatar de manera precisa y directa su relación con el huinca (el hombre blanco) en términos culturales y económicos. Tal fusión de voces desestabiliza la voz narrativa de Koessler-Ilg puesto que ella alterna entre la primera persona y la tercera cuando se refiere a sí misma en el libro. Pero además, subvierte ideologías patriarcales más tradicionales al narrar su propio trabajo profesional de folkloróloga, y el de las machis, situándolo simbólicamente al mismo nivel de importancia que las actividades de su esposo. A la vez, Koessler-Ilg escribe para incorporar sus obras en un archivo cultural que dé testimonio de las obras de alemanes en el interior argentino y para conservar la herencia cultural de sus amigos mapuches. Es decir, la estructura misma del texto sirve como zona de contacto en la que KoesslerIlg emplea discursos y patrones de su herencia alemana y de Argentina para suturar una identidad germano-argentina nueva -la de mediadora entre tres culturas, la alemana, la argentina y la mapuche-.

Textos como Der Medizinmann am Lanin presentan cualidades relacionadas con el género ensayo que les permiten ser empleados en campos variados desde la literatura hasta la política, la historia y la antropología. Según ha indicado el crítico Pablo Heredia, el ensayo asume la convergencia de discursos de conocimiento como el científico y el artístico, y sirve para promover agendas retóricas que aspiran a representar una verdad, ideas y una realidad (53). Semejante a Heredia, Álvaro Fernández Bravo afirma que muchos de los ensayos (informes de viajes y crónicas) decimonónicos tardíos que se ocupan de zonas fronterizas como Patagonia son textos híbridos y etnográficos que utilizan el discurso científico para colonizar el espacio a través de la literatura e incorporarlo a la nación argentina. De esta manera, los escritores argentinos empleaban la literatura para cubrir espacios fronterizos con palabras, descubrir el pasado, retratar,

\footnotetext{
Revista Iberoamericana, Vol. LXXVII, Núms. 236-237, Julio-Diciembre 2011, 1001-1018
ISSN 2154-4794 (Electrónico)
} 
interrogar y clasificar tipos sociales y sus costumbres, siempre en el marco de la nación (Fernández Bravo 12, 17). En efecto, la literatura en el siglo xix suponía la capacidad de representar e incorporar espacios geográficos por medio de la transcripción narrativa. Der Medizinman am Lanin de Bertha Koessler-Ilg manifiesta los rasgos que indica Heredia, así como muchas de las características ambiguas que Fernández Bravo incluye en la categoría que llama "Literatura Fronteriza”. La narrativa de Koessler-Ilg, tanto como las de sus precursores y contemporáneos argentinos, tiene características etnográficas particulares que demuestran cómo un género difuso se usó para transcribir una región en un formato realista, relatar las prácticas y tradiciones amerindias, inscribir las obras de inmigrantes alemanes como ella misma y su esposo en proyectos de construcción, y también para crear una representación textual de un espacio social en Patagonia. Lo notable es que inserta su texto, escrito en alemán por una mujer, en un espacio dominado más bien por hombres cuyas obras aparecen en castellano.

\section{CONCLUSIÓN}

Actualmente se ha renovado el interés en el estudio del mantenimiento del Deutschtum y en la creación de Heimat (patria) por parte de comunidades alemanas en el extranjero. Investigaciones sobre dichos temas se han realizado desde disciplinas como la historia, la lingüística y la literatura en el campo de estudios culturales germanos, y evidencian distintos grados de contacto y asimilación entre inmigrantes alemanes y sus países anfitriones. ${ }^{21}$ Estos trabajos ofrecen perspectivas mucho más complejas sobre los objetivos, interacciones y formación identitaria de estos inmigrantes. Sin embargo, son análisis desde la perspectiva de los estudios germánicos; faltan, pues, investigaciones desde el campo de los estudios latinoamericanos para entender mejor la dinámica no sólo entre huéspedes y anfitriones, sino también entre las diversas generaciones que forman las comunidades alemanas en Latinoamérica.

Publicado en un momento crítico, Der Medizinmann am Lanin apela a un público lector binacional de clase media y alta. Invoca dos herencias (la germana y la argentina) y crea una representación cultural dual que combina las tradiciones alemana y argentina. Koessler-Ilg asume el papel tradicional femenino como protectora del Deutschtum, destacando las obras positivas de los alemanes en la Patagonia argentina en una época de cambios de percepción hacia la colectividad residente, dados los escándalos revelados en la prensa bonaerense respecto a un complot patagónico y también por las agresiones del estado alemán en Europa a fines de la década de 1930. El libro se puede interpretar como un gesto político puesto que formó parte de una serie titulada "Deutsches Werk in Südamerika” y trata de los aportes de los inmigrantes germanos en el país adoptivo.

${ }^{21}$ Ver O’Donnell y otros (2005) y Schulze (2008).

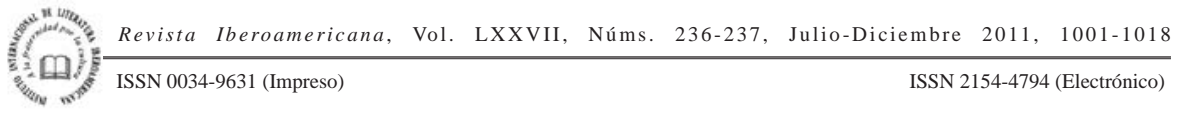


Dicha serie, y Koessler-Ilg en particular, exige de sus lectores el reconocimiento de los sacrificios germanos al proyecto de construcción nacional argentino. El hecho de que la obra se escribió y circuló en alemán llama mucho la atención. Vista como respuesta y defensa frente a su contexto histórico, Der Medizinmann am Lanin parece reforzar la cohesión al interior de la comunidad alemana y calmar las dudas de los miembros de la oligarquía argentina de ascendencia germana con respecto a la lealtad y adhesión de otros alemanes menos asimilados a la cultura dominante argentina.

Der Medizinmann am Lanin revela además cómo una mujer inmigrante alemana se reinventa en Argentina, como mujer profesional y folkloróloga, y reclama la misma consideración y reconocimiento por sus obras que su esposo médico. El texto y su forma le permiten a la autora asumir el papel tradicional de mujer protectora de Deutschtum y simultáneamente salir de este mismo rol. Como autoetnografía, el libro le brinda la oportunidad de escribir los hechos de su familia en un contexto histórico específico y su estructura híbrida deja ver la zona de contacto que es San Martín de los Andes en la época. Las anécdotas relatadas demuestran la negociación y convivencia entre una familia de inmigrantes y sus vecinos mestizos y amerindios en un lugar fronterizo del país. Al recolectar cuentos folklóricos mapuches y reconocer el desvanecimiento de su cultura aborigen, el libro de Koessler-Ilg sugiere que poblaciones como las de inmigrantes alemanes llenan este supuesto vacío geográfico y cultural para contribuir a la realización de proyectos de desarrollo y cimentación nacional iniciados en el siglo xIX.

Las características del texto de Koessler-Ilg como autoetnografía y como lugar de sutura son de suma importancia porque pueden apuntar a un patrón en la producción de obras escritas por inmigrantes en Argentina. Existen otros textos con rasgos y temas parecidos como, por ejemplo, Ella und der Gringo mit den großen Füßen [Ella y el gringo con los pies grandes] de Ella Brunswig, otra alemana expatriada radicada en la Patagonia argentina en la década de 1920. Basado en cartas que escribió a su madre en Berlín, en los recuerdos de su hija y en un par de ensayos de su esposo, su libro también confirma una estructura híbrida que problematiza cuestiones de patriotismo, género y asimilación en el país adoptivo. El hecho de que últimamente textos de inmigrantes alemanes como los de Koessler-Ilg y Brunswig se están traduciendo del alemán al castellano en Argentina por sus hijos y nietos también llama la atención porque requiere el reconocimiento de un público argentino y un análisis dentro de los estudios latinoamericanos actuales. ${ }^{22}$

${ }_{22}$ Como se ha mencionado, encontrar ejemplos de este corpus exige trabajo de archivo adicional. No obstante, existen puntos de partida para estudios comparados. Publicaciones como Historias de inmigración. Testimonios de pasión, amor y arraigo en tierra argentina, 1850-1950 de Lucía Gálvez y Mujeres en tierra de hombres. Historias reales de la Patagonia invisible de Virginia Haurie ofrecen valiosa información de archivo para el investigador. Gálvez incluye memorias de diversos inmigrantes, narradas por los protagonistas o sus descendientes, en tanto que Haurie narra las historias de mujeres inmigrantes en su viaje a la Patagonia.

Revista Iberoamericana, Vol. LXXVII, Núms. 236-237, Julio-Diciembre 2011, 1001-1018
ISSN 0034-9631 (Impreso) 
Alemann, Carmen de. Presencia alemana y austriaca en la Argentina. Buenos Aires: M. Zago, 1985.

Alemann, Theodor. Die Zukunft des Deutschtums in America. Buenos Aires: E. Beutelspacher, 1917.

Bandieri, Susana. Historia de la Patagonia. Buenos Aires: Sudamericana, 2005.

Blanco, Graciela. "Las explotaciones ganaderas en la Patagonia: Sujetos sociales, articulación comercial y organización socio-espacial”. Hecho en Patagonia: La historia en perspectiva regional. Susana Bandieri, et al. eds. Neuquén: Universidad Nacional del Comahue, 2006. 155-89.

Bamberg, Maria. Ella und der Gringo mit den großen Füßen: Eine deutsche Familiengeschichte in Patagonien. 1998. Hamburgo: Rowohlt Taschenbuch Verlag, 2000.

Bernecker, Walther L. y Thomas Fischer. “Alemania y América Latina en la época del imperialismo 1871-1914”. Revista de Historia 33 (1996): 9-42.

Bertoni, Lilia Ana. Patriotas, cosmopolitas y nacionalistas: La construcción de la nacionalidad argentina a fines del siglo XIX. Buenos Aires: Fondo de Cultura Económica, 2001.

Brettell, Carolina B. "Blurred Genres and Blended Voices: Life History, Biography, Autobiography, and the Auto/Ethnography of Women's Lives”. Deborah E ReedDanahay, ed. Auto/Ethnography. Rewriting the Self and the Social. Nueva York: Berg, 1997. 223-46.

Brunswig de Bamberg, María. Allá en la Patagonia. 1995. Buenos Aires: Javier Vergara, 1999.

Castro, Donald S. The Development and Politics of Argentine Immigration Policy 18521914. To Govern is to Populate. Diss. San Francisco: Mellon Research UP, 1991.

Devoto, Fernando. Historia de la inmigración en la Argentina. Buenos Aires: Editorial Sudamericana, 2003.

Fernández Bravo, Álvaro. Literatura y frontera. Procesos de territorialización en las culturas argentina y chilena del siglo XIX. Buenos Aires: Editorial Sudamericana, 1999.

Forbes, Ian L.D. "German Informal Imperialism in South America before 1914". Economic History Review 31 (1978): 384-98.

Gálvez, Lucía. Historias de inmigración. Testimonios de pasión, amor y arraigo en tierra argentina, 1850-1950. Buenos Aires: Norma, 2003.

Hall, Stuart y Paul Du Gay. Questions of Cultural Identity. Londres: Sage, 1996.

Haurie, Virginia. Mujeres en tierra de hombres. Historias reales de la Patagonia invisible. Buenos Aires: Sudamericana, 1996.

Revista Iberoamericana, Vol. LXXVII, Núms. 236-237, Julio-Diciembre 2011, 1001-1018
ISSN 2154-4794 (Electrónico) 
Heredia, Pablo. "Proyectos de integración regional. El ensayo moderno argentino 18901920”. Espacios neoculturales. Diseños de la nación en los discursos literarios del Cono Sur 1880-1930. Córdoba: Alción, 2000. 51-83.

Hesse, Max René. Morath schlägt sich durch. Berlín: B. Cassirer, 1933. Morath verwirklicht einen traum. Berlín: B. Cassirer, 1933.

Koessler-Ilg, Bertha. Der Medizinmann am Lanin. Von der Arbeit eines deutschen Arztes in der patagonischen Kordillere. Buenos Aires: E. Beutelspacher, 1940.

El Machi de Lanín. Un médico alemán en la cordillera patagónica. Buenos Aires: El Elefante Blanco, 2003.

Maltesische Märchen und Schwänke aus dem Volksmunde gessammelt. Leipzig:

G. Schönfeld, 1906.

y Hans Stumme. Maltesische Volkslieder im Urtext mit deutscher Übersetzung. Leipzig: J.C. Hinrichs, 1909.

LaVigne, Madelyn Witt. Heartland Germans: Cultural Maintenance in Mid-Nineteenth Century America. Tesis de maestría. Florida Atlantic University, 2006.

Lorenzkowski, Barbara. Border Crossings: The Making of German Identities in the New World, 1850-1914. Tesis doctoral. University of Ottawa, 2002. Ottawa: Bibliothèque Nationale du Canada, 2003.

Luebke, Frederick C. Germans in the New World: Essays in the History of Immigration. Urbana: U of Illinois P, 1990.

Museo Genaro Pérez. “Mariano Barilari”. 2 agosto. 2008. <http://www.agora.com.ar/ museogp/mt2005/mtemp-MB.htm>.

Newton, Ronald C. German Buenos Aires, 1900-1933: Social Change and Cultural Crisis. Austin: U of Texas P, 1977.

The 'Nazi Menace’ in Argentina, 1931-1947. Stanford: Stanford UP, 1992.

O’Donnell, Krista, Renate Bridenthal y Nancy Ruth Reagin, eds. The Heimat Abroad. The Boundaries of Germanness. Ann Arbor: U of Michigan P, 2005.

"Home, Nation, Empire: Domestic Germanness and Colonial Citizenship”. Krista O’Donnell y otros, eds. The Heimat Abroad. The Boundaries of Germanness. Ann Arbor: U of Michigan P, 2005. 40-58.

Pratt, Mary Louise. Imperial Eyes. Travel Writing and Transculturation. Londres: Routledge, 1992.

Reagin, Nancy R. Sweeping the German Nation: Domesticity and National Identity in Germany. Cambridge: Cambridge UP, 2006.

Reed-Danahay, Deborah, ed. Auto/Ethnography. Rewriting the Self and the Social. Nueva York: Berg, 1997.

Saint Sauveur-Henn, Anne. Un siècle d'émigration vers l'Argentine. Colonia: Böhlau Verlag, 1995.

Schobinger, Juan. Inmigración y colonización suizas en la República Argentina en el siglo XIX. Buenos Aires: Instituto de la Cultura Suizo-Argentino, 1957.

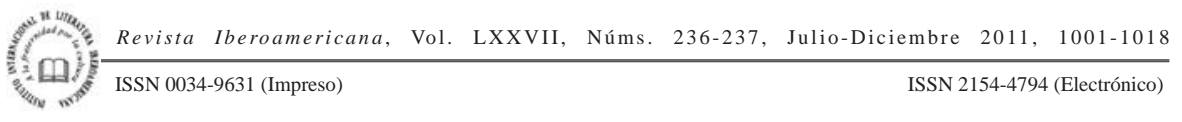


Schreiber, Otto. Im Schatten des Calafate: patagonisches, allzupatagonisches. Berlín: Brunnen Verlag, 1928.

Schulze, Mathias. German Diasporic Experiences. Identity, Migration, and Loss. Waterloo, Ontario: Wilfrid Laurier UP, 2008.

Smith, Woodruff D. The German Colonial Empire. Chapel Hill: U of North Carolina P, 1978.

Torres, Susana. “Grupos inmigratorios y relaciones identitarias en algunos centros urbanos de la Patagonia”. Hecho en Patagonia. La historia en perspectiva regional. Susana Bandieri y otros, eds. Neuquén: Universidad Nacional del Comahue, 2006. 251-78.

Vallejos, Soledad. "Bertha, la araucana blanca”. Página 12: Las 12. (Buenos Aires, 2 mayo 2007). 18 julio 2008. <http://tinyurl.com/4c8gem>.

Wildenthal, Lora. German Women for Empire, 1884-1945. Durham: Duke UP, 2001.

Zago, Manrique, Peter Alemann y Carmen de Alemann. Presencia alemana en la Argentina. Buenos Aires: M. Zago, 1992.

Peter Alemann y Silvia Varela. Los suizos en la Argentina. Buenos Aires: M. Zago, 1995.

ISSN 0034-9631 (Impreso) 